\title{
How to Build a Nest for Success in the Public Health Sector: A Critical Look at the Leadership Theories
}

\author{
Jalal-Eddeen Abubakar Saleh", *, Fadimatu Jalal-Eddeen², Annah Yohanna Kilba ${ }^{2}$ \\ ${ }^{1}$ W.H.O. Bauchi Zonal Office, Bauchi, Nigeria \\ ${ }^{2}$ Department of Economics, College for Continuing Education, Adamawa State Polytechnic, Yola, Nigeria
}

Email address:

drjalals@yahoo.com (Jalal-Eddeen A. S.)

\section{To cite this article:}

Jalal-Eddeen Abubakar Saleh, Fadimatu Jalal-Eddeen, Annah Yohanna Kilba. How to Build a Nest for Success in the Public Health Sector: A Critical Look at the Leadership Theories. Humanities and Social Sciences. Vol. 3, No. 4, 2015, pp. 133-139. doi: 10.11648/j.hss.20150304.12

\begin{abstract}
In this $21^{\text {st }}$ century of technological advancement, it is very clear that the challenges before the public health sector and most importantly the leadership are enormous, spanning from bio-terrorism, the super bugs, drug resistance, emerging and re-emerging infectious diseases, increase in preventable metabolic and nutritional disorders, widening gap between the rich and the poor, and drug companies sponsoring researches for their economic gains. To effectively address these challenges, require public health leaders that have clear understanding and applicability of the various leadership theories. Considering the fact that there is no single theory that is effective within the public health leadership circle, there is need for future public health leaders to look for alternative theories or a combination of theories that would ensure effectiveness in the discharge of their responsibilities to create a nest for success within the public health sector. As public health professionals, we are aware that public health leadership aims to protect the health of the public, promote population health, prevent diseases, assess effectiveness of the health systems, evaluate the impact of interventions, and reduce health inequity and inequality. However, achieving this is only possible when there is in place the right leader at the right time. Thus, public health leaders would require certain traits and skills that enables them build infrastructure that prevent diseases, serve the people, ensure population based approach on public health issues, and create community-wide health strategies to bring the required positive social change. However, this is not possible except when there is the right leadership at the helm of affairs who was able to master the various leadership theories and their applicability.
\end{abstract}

Keywords: Multicultural Leadership, Skills Versus Traits, The Systems Perspective, Emotional Intelligence, Path-Goal, Situational Theories of Leadership, The Leader-Member Exchange Theory, Social Network Theory

\section{Introduction}

The 21st century, considered as an era of globalization and global health governance, has underscored the fact that globalization has improved not only global trading and advancement in information-communication technology but also the practice of public health. ${ }^{1}$ The advances recorded in the area of global public health, such as increase accessibility of public health goods by developing countries from the advanced economies of the world, and the constant interaction of public health leaders at a global level has created the need for public health leaders to have multicultural awareness. This enables the public health leadership to understand the cultural norms of the various countries and to create cultural sensitivity when dealing with issues of public health importance. ${ }^{1}$

\section{Multicultural Leadership: Leadership Within A Global Context}

Acquiring these multicultural skills gives the public health leaders various opportunities such as the ability to communicate effectively in a multicultural setting, to set standard procedural guidelines, to create better understanding of systems, to remove barriers while interacting with the locals and to promote good working relationship with their peers within the public health circle. ${ }^{1}$

In public health leadership circle, the need to create social change requires leaders to have a clear understanding of the concept multicultural leadership and the challenges it poses. Importantly, multicultural leadership skills forms part of the requirements of public health leadership hence the need for 
public health leaders to be culturally sensitive and to clearly understand the needs of the people. This is considered as one of the things that assist public health leaders in creating programs that would narrow the gap between rich and poor, to effectively reach out to the underserved, to create a society that is equal to all, to make public health goods readily available and accessible irrespective of their socioeconomic background, and to create policies and programs that would ensure people live and retire into old age in good health irrespective of their cultural links. ${ }^{1,2}$

It is encouraging to note that the concept of multicultural leadership is now receiving increase global attention; this has made various countries across the globe to design managerial and organizational style of leadership with special consideration to the cultural background of their people to conscientiously address their cultural needs. However, there are countries such as the U.S. and U.K., which are lowcontext countries and are more inclined to verbal messages. There are some countries spanning from developed, midincome and developing countries which focus on: nonverbal clues, situational factors, and communication (e.g. Japan, Italy, China, Saudi Arabia) and are referred to as high-context countries. These latter countries consider trust, subtle body gesture and position among other things with regards to how a person reacts to and how others react to them as well. ${ }^{1}$

The two challenges that could be faced by public health leaders while dealing with issues of public health importance are: communication gap between partners and the locals, and lack cultural sensitivity by the programs officers. ${ }^{1}$ As noted with some public health intervention activities such as the polio eradication activities, which often targets the underserved communities considered as the beneficiaries of most public health interventions; the people are likely to be illiterates because they have little or no western education and often with strong religious beliefs. ${ }^{3,4,5}$ These locals often misconceive programs that are meant to address their public health needs thus resulting in program failure with little or no recorded success. Furthermore, this lack of cultural awareness and the lack of cultural sensitivity by some international partner agencies and foreign funders of the program on norms of the locals sometimes add to these problems leading to rejection of the intervention by the locals. $^{6}$

To achieve the desired objectives clearly require developing strategies that would address these challenges; some of these strategies include the need for public health leaders to consider cultural sensitivity when designing programs meant for countries that have strong cultural values, and the public health leadership circle should be familiar with the global cultural diversity to understand the cultural norms of different class of people to enable them be culturally sensitive when dealing with especially people from the low-context countries. The way to address this would be through training of the top management public health leaders, creating workshops and seminars that empower the leadership with the cross-cultural skills, creating intercultural sensitivity and cultural intelligence to enable the leadership have effective means of communication. ${ }^{1,7}$ Additionally, there is the need for public health leaders to understand the concept of "crisis and risk communication" to effectively communicate to the community and bring the desired social change. ${ }^{1,7}$ This could only be achieved through effective health communication skills for the target audience to be well informed on risk and crisis situations. Thus, the public health leadership should have a good understanding of what health education is all about to effectively reaching out to the community. The term health education as defined by the $\mathrm{CDC}$, is "the study and use of communication strategies to inform and influence individual and community decisions that enhance health."

\section{Skills Versus Traits and The Systems Perspective}

The increasing threat to the global public health leadership could be as a result of increasing challenges in the area bioterrorism, the super bugs, drug resistance, emerging and reemerging infectious diseases, increase in preventable metabolic and nutritional disorders such as cardiovascular diseases, obesity, diabetes, increasing gap between the rich and the poor, and drug companies sponsoring researches for their economic gains at the expense of the public to mention but a few. Thus public health leaders should once again understand the concept of 'skills approach', 'trait theory' and 'systems thinking'. It is also important for leaders in the public health sector to be able to clearly distinguish between heritable attributes that produce effective leaders from nonleaders and also the persons' effectiveness as a leader within the circle of public health; this is aimed at empowering leaders to bring the much desired social change to the communities. $^{1,9}$

The concept of 'skills approach' in leadership, as highlighted by some authorities within the leadership circle, has to do with the capabilities of a leader to adequately meet up with the challenges in the environment that he operates; however, this is contrast to the 'trait approach', which has to do with inherent attributes present in the leader. Although there is a clear distinction between these two approaches, there is need for the two to work in tandem to produce an effective. ${ }^{1,9}$ There is need to underscore that the concept of skills approach and trait theory should aim to focus on the various aspects of leadership to bring out the requirements of an effective leader and also serve as a standard measure when assessing leaders. ${ }^{1,9}$ Furthermore, the issue of leadership should be based on "capabilities, knowledge, and skills", which are considered as important components required in leadership to bring social change to the community. ${ }^{9}$

As observed, skills help leaders to use their experiences, knowledge, acumen, vision, and perceptions in proffering solutions to problems and to positively transform the lives of their populace. ${ }^{9}$ Thus, there is the need to emphasize that interpersonal skills and social cognition in leadership are important requirements for leaders to relate well with their 
sub-ordinates; this is in consonant with the ideals of trait theories as well skills approach in public health leadership.,

Additionally, skills approach and trait theory in leadership are interrelated within the leadership circle; thus these two are not mutually exclusive as neither skills approach nor traits could operate in isolation to make an effective public health leader who would bring the desired social change. There are several literature on leadership that supports this argument, emphasizing that attributes such as skills, capabilities, demographics and personality traits are considered as predictors of good leadership. ${ }^{10,11,12}$ Furthermore, an interpersonal attribute, which is a category of leadership traits, requires leaders to have effective communication skills and abilities; these are also important components of skills approaches vis-à-vis social functions. ${ }^{13}$

In the skills approach, environmental factors considered as important determinants could be acquired through hard work, daily routines, and education among others. In some situations, environment plays a role in the trait theory; this is in spite the fact that inherent biological factors are also important determinants. ${ }^{1,9,14,15}$ Thus, there is need for future public health leaders to have a clear understanding of this concept towards assessing leaders' skills, traits, strengths, and weaknesses; this is to ensure that the outlined aims and objectives in every leadership are achieved through building a dedicated and focused team. This would also help public health leaders have the requisite knowledge that would enable them to recognize and have a good understanding of the components that makes up an effective leader.

\section{Behavioral/Style Perspective to Leadership}

The fact that leadership style/behaviours emanated from philosophy, personality and experience of leaders, is considered as one of the ways leaders behave while discharging their responsibilities. ${ }^{16,17}$ In transformational leadership style, the attributes of an effective leader include his ability to motivate, his inspirational motivation, his intellectual stimulation, and his individualized consideration. It has been shown that transformational leaders have the ability to positively change the cultural orientation of an organization, meet the demands of its environment in accordance with systems approach, motivate their followers to enable them accomplish more than what they initially planned to accomplish and makes them effective and efficient. $^{18,19}$

\section{Emotional Intelligence}

Emotional intelligence (EI), first defined by Peter Salovey and John Mayer in 1990, describes intelligence from the social and interpersonal perspectives. ${ }^{1}$ In the modern concept of public health leadership, it is re-assuring to note that Emotional Intelligence (EI) has given leaders wide range of skills that enables them network with individuals, manage relationships, as well as inspire and encourage people to give in their best. In the effective discharge of leadership responsibilities, there are important components of the EI considered essential for a leader to possess; these include self-awareness, self-motivation, empathy for others, social skills, and managing emotions and self-regulation. ${ }^{1}$ There are components of EI, which could be considered essential in leadership for effective discharge of responsibilities; these are: self-awareness, emotional management, effective communications, social awareness and conflict resolutions. ${ }^{20}$

Emotional Intelligence has now received a wider applicability in the modern public health leadership circle; this is supported by the works of Goleman (1995) who explained that EI contributes at least $80 \%$ of individual's successes in life and that the remaining 20 percent was due to differences in IQ of individuals. ${ }^{21}$ Furthermore, Lynn (2008) has also shown that Emotional Intelligence competencies account for between 24 to 69 per cent of performance success of leaders hence the need to understand the concept very well. $^{22}$

Thus, EI gives public health leaders the wide range of skills that enables them network with individuals, manage relationships, inspire as well as encourage people to give in their best.

\section{Adapting to Changes - The Situational Leadership}

It is on record that approaches to problem of leadership usually fall under one of these three theories: trait theories, style theories and contingency theories. ${ }^{16}$ Theorists defined this style of leadership as contingent to the situation, which is sometimes, classified as contingency theory. Three contingency leadership theories appear more prominently in recent years: Fiedler contingency model, Vroom-Yetton decision model, and the Hersey-Blanchard situational theory. $1,16,17$

Spencer (1881) said that it is time that produces the person and not the other way around; this theory assumes that different situations call for different characteristics; according to this group of theories, no single optimal psychographic profile of a leader exists. It is clear that what an individual does as a leader is largely dependent upon characteristics of the situation in which he as a leader functions. ${ }^{1,16,17,23}$ Thus, some theorists started to synthesize the trait and situational approaches, and started building upon the research of earlier theorists. ${ }^{24}$ As a result of this scholars began to normalize the descriptive models of leadership climates, defining three leadership styles and identifying which situations each style works better in:

i. The authoritarian leadership style, approved in periods of crisis but fails to win the "hearts and minds" of their followers in the day-to-day management;

ii. The democratic leadership style is more adequate in situations that require consensus building 
iii. The laissez faire leadership style appreciated by the degree of freedom it provides, but as the leader does not "take charge", he can be perceived as a failure in protracted or thorny organizational problems.

Theorists defined this style of leadership as contingent to the situation, which is sometimes, classified as contingency theory. The three contingency leadership theories appear more prominently in recent years are Fiedler contingency model, Vroom-Yetton decision model, and the HerseyBlanchard situational theory. ${ }^{17}$

a. The Fiedler contingency model is based on the leader's effectiveness on what Fred Fiedler called situational contingency. This results from the interaction of leadership style and situational favorableness (later called "situational control"). The theory defined two types of leader: those who tend to accomplish the task by developing good-relationships with the group (relationship-oriented), and those who have as their prime concern carrying out the task itself (taskoriented). According to Fiedler, there is no ideal leader. Both task-oriented and relationship-oriented leaders can be effective if their leadership orientation fits the situation. When there is a good leader-member relation, a highly structured task, and high leader position power, the situation is considered a "favorable situation". Fiedler found that task-oriented leaders are more effective in extremely favourable or unfavourable situations, whereas relationship-oriented leaders perform best in situations with intermediate favourability. ${ }^{17}$

b. Vroom in collaboration with Yetton and with Jago developed a taxonomy for describing leadership situations; this taxonomy was used in a normative decision model where leadership styles were connected to situational variables, defining which approach was more suitable to which situation. ${ }^{15,17}$ This approach was new because it supported the idea that the same leader could rely on different group decision-making approaches depending on the attributes of each situation. This model was later referred as situational contingency theory.

c. The situational leadership model proposed by Hersey and Blanchard suggests four leadership-styles and four levels of follower-development. For effectiveness, the model posits that the leadership-style must match the appropriate level of followership-development. In this model, leadership behavior becomes a function not only of the characteristics of the leader, but of the other players as well as the followers. ${ }^{25}$ However, Fernandez model of situational leadership also considered this as shared leadership due to the collective spirit and shared roles of the key players spanning from the leadership at the top, the managers, supervisors, as well as top executives within the sector. ${ }^{23}$

The two strengths of situational approach are:

- It develop leaders whose feelings are the people first with a view to bringing positive changes in their lives or working environment. It makes leadership behavior to become a function not only of the characteristics of the leader, but of the followers as well

- It prepares the mind-set of a leader on situations enabling him have a broader perspective towards controlling problems that could otherwise affect the way the system work

The two limitations of situational approach are:

- It may not positively address the needs of the people especially if during period of crisis it turned out to authoritarian leadership. This is because it would fail to win the hearts and minds of the people in their day-today activities

- It does not address the needs of the people hence is an incomplete leadership approach hence the need for further research to modify this theory and develop a more conscientious leadership theory that would serve the need of the populace.

\section{The Leader-Member Exchange (LMX) Theory and Social Network (SN)}

The concept of Leader-Member Exchange (LMX) Theory and Social Network (SN) Theory became an important component of the leadership theories, hence the need to have a clear understanding of the concept so as to bring effectiveness in leadership to create positive professional relationships with the subordinates that aims to prevent breaks in relationships to guide organizations toward achieving success. The need to build a nest for success that would enable public health leaders to bring positive social change to the community require the leader to effectively communication and create relationships with the subordinates. This is possible through incorporating the LMX and SN into the public health leadership to foster a better relationship between the leader and his sub-ordinates. ${ }^{1}$

The two theories (LMX and SN) clearly remind us on the importance of building relationships. The LMX emphasizes on leaders to establish one-on-one relationship with their subordinates, which in turn depends on quality of the exchange. LMX, in which culture plays a vital role vis-à-vis assigning sub-ordinates to groups, "focuses on the unique, relationshipbased exchange between and followers." The relationship between the leader and his sub-ordinates could be in the form of in-groups and out-groups and these are based on honesty, openness, respect, and trustworthiness. ${ }^{1}$

The in-groups shares high quality LMX while the outgroups shares low-quality LMX; these two groups could be viewed from two opposite ends of a scale. ${ }^{26}$ This high quality LMX is based on these following four components: contribution, loyalty, affect, and professional respect. ${ }^{27}$ The out-group members are considered as less responsible and the leader often gives them less challenging tasks with little opportunities for promotion. The leaders here benefit from high-quality LMX such as: support from members, reputation, prestige, and, as well as increased chance of promotion and 
leader job satisfaction. $^{28}$

The Social Network Theory (SNT) considers relationships at individual participants and between participants to form a network. This is basically a way of creating relationships with network of people in an organization and reminds us of the networks of people or communities. ${ }^{29}$ The SNT sees relationships from a different perspective and has no relationships at that level; the focus is on how the relationships are formed. The SNT sees the relationships themselves and on how they are formed; it has no link to specific traits or features, which symbolises the individual as important. The ties that created this network are equivalent to the relationships between leaders and followers in the LMX. ${ }^{1}$ The need to empower followers towards achieving goals forms an important reason for alliances to exist between leaders and their subordinates so as to create positive influence. These alliances could be considered as similar to the network of ties as viewed by the SNT. It is important to remember that the SNT has remarkable influence on reputation, power, and stability of an individual and the organization as a whole. The more diverse a social network is, the more resilient, stable, and powerful the individual or group would be; this translates into positive organizational performance. $^{29}$

The difference between LMX and SNT is that unlike SNT, the LMX emphasis is on the significance of the actual relationships, whereas SNT, which has its roots from the cognitive theory, gives consideration on ways through which individuals create or recognize relationships vis-à-vis job performance. ${ }^{30}$ This is an approach that could be helpful when viewing lack of agreement between the leader and an individual member (such as formation of the relationship, length and duration of interactions), which is in agreement with the LMX. These two theories, when integrated together, could positively fit in with the situational approaches.

\section{Path-Goal and Situational Theories of Leadership}

As mentioned earlier, globally the challenges to public health leadership are on the increase. This ranges from existing diseases, emerging and remerging diseases, bioterrorism, natural and man-made disasters to mention but a few. It is as a result of these and other similar leadership challenges that existed in the past that made theorists began to conjecture that the secret to good leadership depends on the style of the leader, the nature of task involved, and the situation or the characteristics of his personality. In view of the fact that there is no assured guarantee that people in leadership positions would succeed at all times, theorists suggested the need for leaders to have a very good understanding of the concept of leadership to enable them become effective leaders and succeed. ${ }^{1,16,17}$

The Path Goal approach was first suggested by Georgopoulous, Mahoney and Jones in 1957 and then reproduced in Vroom and Deci. ${ }^{16,17}$ The Path Goal Theory
(PGT) has its roots from the situational theory, the expectancy theory, and the contingency theory; it is considered by some as being more complex and unreasonable with lots of assumptions when looked at more closely. It aims at leadership removing obstacles as well as providing support to the subordinates to enable both sides achieve their outlined goals. ${ }^{1,31}$ The PGT has well-defined objectives such as: defining the goal, clarifying the path, removing the obstacles and providing support to the subordinates. ${ }^{31}$

The strengths of the PGT, to some degree, include the fact that we can control our own destiny and responses to pressure, thus paving ways to select our goals and choose the paths towards them. ${ }^{16,17}$ The PGT uses three basic principle of effective leadership: to direct, to delegate and to support subordinates and their work performance, contributes to our understanding of leadership focussing on providing guidance, and support to the sub-ordinates. ${ }^{1,31}$ The validity of the PGT could be supported by the leadership of Stachowiak, who acted to create networks that rendered support and provided solutions towards strengthening her organization in Russia to address the 1993 health crisis. Stachowiak, ably established clear directives for her subordinates and created the right connections with appropriate agencies to achieve her outlined goals. $^{32}$

The limitations of the PGT are that the theory employs so much assumptions which arguably may not be easily applicable in some large organizations and thus its inability to adequately explain the association between behavioural leadership vis-a-vis worker motivation. ${ }^{16,17,31}$

It is important to note that the PGT has some similarities with the Situational Leadership Theory (SLT) especially that the PGT emerged from the SLT. The PGT and the SLT theories look at leadership's influence on task accomplishment of the subordinates. Additionally, the two theories have similar attributes such as defining the goal (achievement-oriented), clarifying the path (participative), removing the obstacles and providing support to the subordinates (being considerate). ${ }^{16,33}$ While the PGT looks at subordinates' motivation and satisfaction aimed at task accomplishment, the SLT emphasises on subordinates willingness to accomplish a task with inputs from the leader. $^{1,16,17}$

\section{Conclusion}

Looking at the increasing challenges that the public health sector faces, it is paramount for public health leaders to understand the various leadership theories to effectively prepare them in building the right infrastructure that would prevent diseases, ensure population based approach on public health issues, create strategies that aims to prevent diseases, protect and promote good health, and have in place the right approach for community-wide health strategies.

It is only when public health professionals clearly understanding the various leadership theories and their applicability, that they would be able to effectively apply them for organizations to succeed in their discharge of 
responsibilities to the wider communities. Thus, the need for leaders to be conscious of multicultural awareness and to be sensitive to the needs of the community as they are critical in determining appropriate actions, attitudes, and expectations. It is necessary to note 'skills' and 'trait' vis-à-vis systems thinking approaches within the leadership circle operate in tandem; these when combined together would effectively address population health issues, reduce health inequity and inequality and bring social change to the respective communities.

\section{References}

[1] Nahavandi, A. (2012). The art and science of leadership (6th ed.). Upper Saddle River, NJ: Pearson.

[2] Pomerleau, J. and McKee, M. (2005). Issues in Public Health $\left(1^{\text {st }}\right.$ ed.). England: Open University Press.

[3] WHO (2003). Global polio eradication initiative progress report 2002

[4] Yahya, M. (2006). Polio vaccines - "no thank you!" barriers to polio eradication in Northern Nigeria. Oxford Journals Social Sciences, African Affairs 106(423),185-204.

[5] Cook, J.G. and Tahir, F. (2012). Polio in Nigeria: the race to eradication. A report of the CSIS Global Health Policy Centre. Centre for Strategic and International Studies

[6] Global Polio Eradication Initiative (2013). Retrieved from http://www.polioeradication.org/

[7] Bücker, J. and Poutsma, E. (2010). Global management competencies: a theoretical foundation. Journal of Managerial Psychology, 25(8).

[8] Centers for Disease Control and Prevention (2001). U.S. Department of Health and Human Services (USDHHS).

[9] Mumford, M. D., Zaccaro, S. J., Harding, F. D., Jacobs, T. O., \& Fleishman, E. A. (2000). Leadership skills for a changing world: Solving complex social problems. The Leadership Quarterly, 11(1), 11-35. Retrieved from the Walden Library databases.

[10] Judge, T. A., Bono, J. E., Ilies, R., \& Gerhardt, M. W. (2002). Personality and leadership: A qualitative and quantitative review. Journal of Applied Psychology, 87, 765-780.

[11] Judge, T. A., Colbert, A. E., \& Ilies, R. (2004). Intelligence and leadership: A quantitative review and test of theoretical propositions. Journal of Applied Psychology, 89, 542-552.

[12] Mumford, T. V., Campion, M. A., \& Morgeson, F. P. (2007). The leadership skills strataplex: Leadership skill requirements across organizational levels. Leadership Quarterly, 18, 154166.

[13] Klimoski, R. J., \& Hayes, N. J. (1980). Leader-Behavior and Subordinate Motivation. Personnel Psychology, 33, 543-555.

[14] Trochim, W. M., Cabrera, D.A., Milstein, B., Gallagher, R.S., \& Leischow, S.J. (2006). Practical challenges of systems thinking and modeling in Public Health. American Journal of Public Health, 96(3), 538-546.
[15] Vroom, V. H., \& Jago, A.G. (2007). The role of the situation in leadership. American Psychologist, 62(1), 17-24.

[16] Handy, C (1993). Understanding Organizations. $4^{\text {th }}$ ed, Penguin Books.

[17] Huczynski, A. A. and Buchanan, D. A. (2007). The organizational Behavior. $6^{\text {th }}$ ed, Prentice Hall.

[18] Borkowski, N., Deckard, G., Weber, M., Padron, L.A., \& Luongo, S. (2011). Leadership development initiatives underlie individual and system performance in a US public healthcare delivery system, Leadership in Health Services, 24(4), $268-280$.

[19] Burns, J. M. (1978). Leadership: Harper and Row Publishers Inc. New York.

[20] Fletcher, S. (2012). 5 Reasons why emotional intelligence is critical for leaders. Lead change group. Retrieved from http://leadchangegroup.com/5-reasons-why-emotionalintelligence-is-critical-for-leaders/

[21] Goleman, D. (1995). Emotional Intelligence. Bantam, New York, USA.

[22] Lynn, A. (2008). The EQ interview: Finding employees with high emotional intelligence. New York, NY: American Management Association

[23] Fernandez, S., Cho, Y. J., \& Perry, J. L. (2010). Exploring the link between integrated leadership and public sector performance. The Leadership Quarterly, 21(2), 308-3 23

[24] Lewin, K., Lippitt, R. and White, R.K. (1939). "Patterns of aggressive behavior in experimentally created social climates". Journal of Social Psychology 10: 271-301.

[25] Kickul, J. and Neuman, G. (2000). Emergence leadership behaviors: The function of personality and cognitive ability in determining teamwork performance and KSAs. Journal of Business and Psychology 15: 27-51.

[26] Jones, J.A. (2005). Gender dissimilarity and leader-member exchange: The mediating effet of communication apprehension. Emerging Leadership Journeys 2(1): 3-16.

[27] Wilson, K. S., Sin, H., \& Conlon, D. E. (2010). What about the leader in leader-member exchange?The impact of resource exchanges and substitutability on the leader. Academy of Management Review, 35(3), 358-372.

[28] Davies, A., Wong, C. A., \& Laschinger, H. (2011). Nurses' participation in personal knowledge transfer: The role of leader-member exchange (LMX) and structural empowerment. Journal of Nursing Management, 19(5), 632-643.

[29] Ethier, J. (2013). Current research in social network theory. Retrieved from www.scribd.com/doc/11171859/CurrentResearch-in-Social-Network-Theory

[30] Balkundi, P. \& Kilduff, M. (2006). The ties that lead: A social network approach to leadership. The Leadership Quarterly 17(4): 419-439.

[31] Path goal theory (2012). Retrieved from http://adrglobal.com/organizational change/path goal theory.htm

[32] Stachowiak, J. (2010). A brief history of CBOs and NGOs in public health. In Igniting the power of community: The role of CBOs and NGOs in global public health. New York, NY: Springer. 
[33] Sarin, S. and O'Connor, G.C. (2009). First among equals: The effect of team leader characteristics on the internal dynamics of cross-functional product development teams. Journal of Product Innovation Management, 26(2), 188-205. 